\title{
INVESTIDAS NEOLIBERAIS NA EDUCAÇÃO DO PARANÁ: UMA LEITURA CRÍTICA DE MATÉRIA JORNALÍSTICA DA AGÊNCIA ESTADUAL DE NOTÍCIAS
}

\author{
Cléber dos Santos Gonçalves*, Maria Luisa Furlan Costa**. \\ Universidade Estadual de Maringá, Programa de Pós-Graduação em Educação, Maringá, PR. E-mail: \\ binho.clebergoncalves@gmail.com
}

\section{RESUMO}

O presente artigo propõe uma leitura crítica, com contribuições da Análise do Discurso (AD), da matéria jornalística Governo e Klabin firmam parceria em projeto de gestão escolar, divulgada pela Agência Estadual de Notícias em 03 de julho de 2017, confrontando-a com as teorias sobre liberalismo/neoliberalismo. Os resultados apontaram que é possível identificar, para além do texto e considerando as condições sociais e históricas da produção, investidas neoliberais na área educacional do estado do Paraná, mesmo que isso se encontre de modo mascarado, sob justificativas que despertem apoio popular. Este estudo leva à inquietude e a um refletir sobre a necessidade de questionamentos sobre o dito e o não-dito.

Palavras-chave: Neoliberalismo; Educação; Paraná.

\section{INVOLVED NEOLIBERALISTS IN PARANÁ EDUCATION: A CRITICAL READING OF JOURNALISTIC MATTERS OF THE STATE NEWS AGENCY}

\begin{abstract}
This article proposes a critical reading, with contributions from the Discourse Analysis (AD), of the journalistic article Government and Klabin establish partnership in school management project, released by the State News Agency on July 3, 2017, confronting it with theories about liberalism / neoliberalism. The results pointed out that it is possible to identify, beyond the text and considering the social and historical conditions of production, neoliberal invests in the educational area of the state of Paraná, even if this is masked, under justifications that arouse popular support. This study leads to restlessness and a reflection on the need for questioning about the said and the unsaid.
\end{abstract}

Keywords: Neoliberalism; Education; Paraná. 


\section{INTRODUÇÃO}

Para além da polarização partidária que permeia o campo político no cenário brasileiro, as discussões acerca das iniciativas que reduzem o papel do Estado em segmentos como o econômico e o social parecem ganhar evidência sob a luz das defesas neoliberais. A área da educação, cujo desenvolvimento se dá de acordo com diferentes políticas de Governo e de Estado, não está alheia a essa ocorrência. Nesse contexto, se existe a necessidade de encontrar amparo popular - manifestado principalmente pelo voto -, para a implantação de políticas públicas e ações que seguem ou não orientações neoliberais, lança-se mão, constantemente, de discursos justificadores, que, ao mesmo tempo em que têm a pretensão de convencer, visam ao fortalecimento das defesas em prol de uma causa.

É importante destacar que tais discursos não trazem sempre de forma explícita as mensagens e os objetivos a eles inerentes, sendo necessário, para uma melhor compreensão, interpretar as palavras e outros elementos comunicativos a partir de uma análise mais profunda e crítica, não os desvinculando do enunciador e das condições sociais e históricas presentes. É com base nesse pensar, que este trabalho visa apresentar uma proposta de leitura crítica, com contribuições da Análise do Discurso Francesa, mais especificamente de conceitos elencados por Foucault relacionados a Discurso e Poder, de uma matéria divulgada pelo governo do estado do Paraná em 03 de julho de 2017: Governo e Klabin firmam parceria em projeto de gestão escolar ${ }^{1}$. Sem a pretensão de esgotar o assunto ou apresentar a possibilidade de uma interpretação única, esse trabalho contribui para a compreensão dos níveis de influências dos ideais neoliberais no desenvolvimento da educação pública.

\section{METODOLOGIA}

A metodologia adotada neste trabalho, para o alcance dos objetivos, teve início com uma pesquisa bibliográfica referencial sobre o neoliberalismo e sua influência na educação, como já se há discorrido e conforme as referências deste trabalho apontam. Além disso, foi preciso lançar mão de contribuições da Análise do Discurso Francesa, principalmente de conceitos de Foucault a respeito de Discurso e Poder, de modo a propor, de maneira mais ordenada, a interpretação da discursividade presente no texto jornalístico.

A partir de então, foi realizada uma leitura crítica de cada parágrafo da matéria jornalística em questão, divulgada pela Agência Estadual de Notícias, em sítio eletrônico próprio e em diferentes plataformas de mídia espalhadas pelo Paraná e pelo Brasil, procurando identificar na discursividade do texto se existem elementos que remetem aos ideais neoliberais.

\section{RESULTADOS}

Apesar de as defesas neoliberais encontrarem respaldo nas iniciativas liberais presentes nos últimos quatro séculos, é na segunda metade do século XVIII que a ideologia passa a contemplar de forma mais veemente os campos da economia e da política. Um dos principais representantes desse movimento é Adam Smith, que escreveu, entre outras produções, a consagrada obra "A Riqueza das Nações", por meio da qual apresenta o livre comércio e a livre competitividade, pela lógica da divisão do trabalho, como mecanismos necessários à estabilidade econômica e política (MORAES, 2001).

Influenciando os setores econômico e político, a defesa dos ideais liberais lançou luz principalmente à diminuição da participação do Estado - sob o argumento da "mão invisível", de Smith, que, apesar de não ser aparente, poderia controlar a qualquer tempo o que ocorria.

[...] uma vez eliminados inteiramente todos os sistemas, sejam eles preferenciais ou de restrições, impõe-se por si mesmo o sistema óbvio e simples da liberdade natural. Deixa-

\footnotetext{
${ }^{1}$ A matéria pode ser encontrada no seguinte endereço eletrônico: http://folhapr.com.br/2017/07/04/governo-e-klabin-firmam-parceria-emprojeto-de-gestao-escolar/. Apesar de ter sido produzida pela Agência Estadual de Notícias, não é possível acessá-la diretamente na fonte neste período, por conta de restrições do período eleitoral.
} 
se a cada qual, enquanto não violar as leis da justiça, perfeita liberdade de ir em busca de seu próprio interesse, a seu próprio modo, e fazer com que tanto seu trabalho como seu capital concorram com os de qualquer outra pessoa ou categoria de pessoas (SMITH, 1983, p. 47).

Tais apontamentos encontraram respaldo no período emergencial do capitalismo. Vencido esse momento de emergência, encontram forças para a manutenção do sistema capitalista, travestidos de novos, como aponta Moraes:

Desse modo, o liberalismo clássico foi em certa medida a ideologia do capitalismo comercial e manufatureiro em expansão e um ataque às regulações políticas produzidas pelas corporações de ofício e pelo Estado mercantilista. Pode-se dizer que o neoliberalismo, de modo semelhante, é a ideologia do capitalismo na era de máxima financeirização da riqueza, a era da riqueza mais líquida, a era do capital volátil e um ataque às formas de regulação econômica do século $\mathrm{XX}$, como o socialismo, 0 keynesianismo, o Estado de bem-estar, o terceiromundismo e o desenvolvimentismo latino-americano (MORAES, 2001, p-p. 3-4).

É a partir da década de 1980 que tais ideais passam a encontrar condições de concretude, com vista à superação de crises e obstáculos econômicos, políticos e sociais (VIANA, 2007). No Brasil, considerando o campo político, o neoliberalismo encontra força a partir de 1989, nos governos de Collor e Fernando Fernando Henrique Cardoso (MORAES, 2001).

Como ocorreu em diferentes estados do país, o Paraná teve e tem os defensores dos mesmos ideais ancorados na corrente neoliberal. No governo por mais de sete anos ininterruptos, o PSDB (Partido da Social Democracia Brasileira), por meio do governador Carlos Alberto Richa, é o mesmo do qual Cardoso, que, durante seu mandato (1995-2003), deixou como registro uma série de privatizações e parcerias público-privadas que, segundo Mendonça (2016), podem ter justificativas encontradas nos ideais neoliberalistas.

De acordo com uma pesquisa realizada pelo Data Folha e divulgada em dezembro de $2017^{2}$, cerca de $70 \%$ da população brasileira é contrária às privatizações, que, como se viu, são uma tendência de iniciativas neoliberais. Por essa razão, a maneira de se discursar a respeito de um determinado assunto torna-se importante para a conquista de apoio popular.

O discurso político, entre mudanças e rupturas próprias de uma democracia, portanto, passa a ter significados para além do dito. No que tange ao recurso da discursividade, por mais que o discurso aparente ser pouca coisa, Foucault (2011) assevera que as interdições que o atingem explicitam uma ligação com o desejo e com o poder.

O discurso - como a psicanálise nos mostrou - não é simplesmente aquilo que manifesta (ou oculta) o desejo; é, também, aquilo que é o objeto do desejo; e visto que - isto a história não cessa de nos ensinar - o discurso não é simplesmente aquilo que traduz as lutas ou os sistemas de dominação, mas aquilo por que, pelo que se luta, o poder do qual nos queremos apoderar (FOUCAULT, 2011, p.10).

Nesse sentido, o discurso é visto como expressão de Poder, já que não pode ser dito por todos. Foucault (2011) reforça que, em uma sociedade, o ato de excluir é frequente, sendo identificado principalmente pela interdição, ou seja, na ação que aponta que não é todo mundo que pode dizer algo de determinado lugar. Segundo o teórico, esse discurso passa a ser considerado, então, um direito privilegiado, só aceito por quem tem atribuída a ele a legitimidade para falar.

Corroborando com esse pensar e expressando a influência neoliberal - inclusive na educação -, Gentili (1996) aponta que a defesa de tal ideal procura, por um lado suprir as crises do capitalismo, por meio de artimanhas e ajustes econômicos, políticos e jurídicos e, por outro,

\footnotetext{
${ }^{2}$ Os resultados da pesquisa podem ser acessados, entre outras plataformas, no seguinte endereço:

https://datafolha.folha.uol.com.br/opiniaopublica/2017/12/1946110-70-sao-contra-privatizacoes-no-brasil.shtml. 
disseminar uma nova concepção de sociedade e de desenvolvimento, impondo um novo jeito de pensar, que contribua para a subsistência do sistema que privilegia os aspectos mercantilistas. Assim, para além das palavras e dos significados imediatos, passa a ser imperativo analisar os discursos originados com base na hegemonia política, de modo a compreender quais são as defesas que estão em jogo, em diferentes momentos históricos. Os posicionamentos políticos e, por vezes, partidários carregam em si, desse modo, objetivos de controle e poder.

\section{DISCUSSÃO}

Tendo-se por base o texto já destacado, pode-se dizer que se trata de uma matéria jornalística, cujo princípio da objetividade subentende-se estar presente. Além disso, outros aspectos devem constar em tipos de textos como este, como informações concretas e reais; destaque dos aspectos principais; e relevância social.

No nível fundamental, é possível perceber a mensagem geral da matéria. O texto apresenta a realização de uma solenidade que formalizou a parceria entre o Governo do Estado do Paraná e a empresa Klabin na gestão de 31 escolas do Paraná. A iniciativa conta com projetos pilotos e tem o objetivo de melhorar os índices educacionais das referidas instituições de ensino. Quem vai investir o dinheiro nessa ação é a empresa Klabin - cerca de R\$ 2 milhões -, em duas etapas, sendo a primeira a realização de um diagnóstico e a segunda a promoção de workshops com funcionários.

Apresentada, de modo geral, a compreensão a partir do primeiro contato com o texto, é necessário lançar um olhar detalhado para um nível mais profundo, que envolve o discurso, com base em mensagens ditas e não ditas. Para tanto, a matéria foi dividida em partes, para uma melhor compreensão. A transcrição literal do texto está em destaque, para diferenciar das considerações próprias deste trabalho. Vejamos:

19 Parte: Título: Governo e Klabin firmam parceria em projeto de gestão escolar

Com base no título, é possível inferir dois aspectos principais: 1ํ) A palavra "Governo", apresentada em primeiro lugar, indica a preocupação em não apontar abandono da responsabilidade do Poder Público para com a educação; 2ㅇ) A palavra "parceria" leva à compreensão de que o Governo estará durante todo o tempo no comando do projeto, como uma das partes responsáveis.

2a Parte: $O$ governador Beto Richa oficializou nesta segunda-feira (03) o projeto de gestão educacional desenvolvido em parceria com Klabin, em 31 escolas da região dos Campos Gerais, onde a empresa tem duas fábricas.

O primeiro parágrafo do texto chama a atenção, primeiramente, por meio da palavra "oficializou", que leva à compreensão de que a iniciativa já encontra respaldo na informalidade. Novamente a palavra "parceria" aparece, com os mesmos objetivos já destacados em relação ao título. Além disso, o fato de o projeto ser desenvolvido na região "onde a empresa tem duas fábricas" pode levar à compreensão de que as instituições privadas, de modo geral, têm responsabilidade com os campos que, comumente, são de responsabilidade do Estado.

3a Parte: $O$ projeto piloto de gestão escolar foi iniciado há seis meses nas escolas dos municípios de Telêmaco Borba, onde está a primeira unidade da Klabin no Paraná; Ortigueira, onde recentemente começou a operar a segunda fábrica da empresa, erguida com apoio do programa Paraná Competitivo, e Imbaú. A iniciativa beneficia cerca de 11 mil estudantes do ensino médio e fundamental.

A expressão "projeto piloto" reforça o entendimento de que a iniciativa não é primária e está, de forma latente, exposta, também, a intenção de reforçar que o projeto tem tudo para dar 
certo, pois já foi aplicado em outros lugares, sendo alguns dos municípios Telêmaco Borba expressão que pode insinuar mais uma vez a responsabilidade da empresa com o local onde está instalada -; e Ortigueira, local onde a empresa passou a atuar recentemente, sendo que a fábrica foi "erguida com apoio do programa Paraná Competitivo". Ora, o Paraná Competitivo é um programa de incentivos fiscais do atual governo. Ou seja, por meio dele, instituições privadas têm isenções de impostos. Isso pode levar a crer que, ao investir em educação pública, a empresa está retribuindo a favores do Estado. Outra expressão que também chama a atenção no trecho é "beneficia cerca de 11 mil estudantes". O verbo é claro ao apontar, mesmo antes dos resultados finais, melhorias na vida dos alunos.

4a Parte: A formalização da parceria foi assinada nesta segunda-feira (3), no Palácio Iguaçu, em reunião do governador, com o diretor-presidente da Klabin, Cristiano Teixeira, e a secretária de Estado da Educação, Ana Seres. A proposta é melhorar os resultados do ensino por meio da gestão das escolas e do aprendizado em sala de aula e, em consequência, elevar o desempenho no Ideb (Índice de Desenvolvimento da Educação Básica).

O primeiro ponto a se destacar no trecho é a presença dos nomes de autoridades, para reforçar a importância e a seriedade da temática. Trata-se de apontar quem tem propriedade e rege a hegemonia política no estado do Paraná. Pode-se destacar, também, a proposta expressa: a de "melhorar os resultados do ensino, por meio da gestão das escolas e do aprendizado em sala de aula", mas tendo como objetivo final "elevar o desempenho no Ideb". Subentende-se, a partir daí que, por mais que o objetivo final sejam aspectos quantitativos, estes estão mascarados pelos qualitativos, para convencer os leitores sobre a importância da medida.

59 Parte: Entre 2017 e 2018, a empresa vai investir $R \$ 2$ milhões na formação continuada de cerca de 890 profissionais da educação. O Governo do Estado cede a estrutura e disponibiliza os profissionais.

O papel da empresa no projeto está claro. Já em relação à atuação do Governo, o trecho restringe-se a apontar, apenas, que este "cede a estrutura e disponibiliza os profissionais". A palavra "ceder" indica noção de pertencimento, como se os profissionais fossem propriedades do Estado.

6a Parte: TEM AÇÃO - A secretária de Estado da Educação, Ana Seres, explicou que o objetivo é a melhoria do processo ensino-aprendizagem por meio de uma gestão escolar eficiente. "Este projeto da Klabin vem para incrementar o que está previsto no nosso principal programa pedagógico, que é o Minha Escola Tem ação - Meta", afirmou a secretária.

Mais uma vez a portadora de poder político hegemônico aparece para explicar a importância da medida, na continuação da proposta de convencimento. Segundo o enunciado, a medida gerará uma gestão eficiente. Isso leva a compreender que a gestão das escolas não tem sido assim a cargo da escola. Ou seja: a ideia é a de que, se houver interesse, é preciso conceder às instituições privadas o controle de processos como este. O que se pode perceber, ainda, é que os profissionais não estão preparados para gerir as instituições escolares. A medida vai ao encontro do programa pedagógico "Minha Escola Tem Ação", que tem por objetivo melhorar os indicadores da educação escolar. O que ocorre, porém, é que, o primeiro caminho apontado pelo programa é "Caminhos da Profissionalização", finalidade que tem tudo a ver com o controle do processo por uma empresa privada.

7a Parte: PILAR - De acordo com o diretor-presidente da Klabin, Cristiano Teixeira, a escolha das escolas que rece- bem o complemento ao Meta partiu da relação entre a empresa $e$ a região em que está instalada. "A educação é um pilar para a Klabin. Procuramos olhar as 
necessidades da região onde a empresa está instalada e oferecer nossa experiência em gestão para melhorar ainda mais o que já é oferecido", explicou. "O projeto complementa o Meta. A primeira parte é ouvir o que já está sendo feito, para justamente conseguirmos alavancar os processos", completou.

Uma vez mais uma autoridade fazendo uso do discurso, como empoderamento concedido a ela. A justificativa, de acordo com o diretor-presidente da instituição, está na "relação entre a empresa e a região na qual está instalada", o que reforça a necessidade de investir em educação como um retorno e uma ação social, de boa vontade. Ele diz também que procuram "melhorar ainda mais o que é oferecido", numa intenção clara de apontar que, apesar de todos os esforços positivos feitos pelo atual governo, existe mais que pode ser feito e isso passa pela participação das empresas privadas no campo educacional.

8a Parte: DIAGNÓSTICO - O projeto tem curadoria do Instituto Falconi e é dividido em etapas. A primeira, já concluída, consistiu em um diagnóstico da realidade de gestão das escolas e da região. $O$ diagnóstico foi apresentado para a equipe da Secretaria da Educação, na manhã desta segunda-feira (03). A segunda etapa irá desenvolver as ações para melhoria como workshops e treinamentos para a equipe administrativa das escolas contempladas, por fim apresentação dos resultados. As oficinas são direcionadas aos professores e diretores das escolas desses municípios, além dos profissionais do Núcleo Regional de Educação de Telêmaco Borba. Serão abordadas práticas de gestão e liderança que buscam melhorar os resultados educacionais e desenvolver a prática da cultura de gestão para resultados nas escolas.

Aqui, está indicada a curadoria do Instituto Falconi, que, de acordo com informações do endereço eletrônico da organização ${ }^{3}$, "é reconhecida pela capacidade de ajudar as organizações a construir resultados excepcionais pelo aperfeiçoamento de seu sistema de gestão. Fundada pelo Professor Vicente Falconi, atua há mais de 30 anos no mercado". Com isso, se vê, novamente, o discurso carregado de justificativas que apontam a necessidade da medida.

9a Parte: PARANÁ COMPETITIVO - Instalada em Ortigueira, a fábrica de celulose da Klabin é o maior investimento privado do Paraná, que criou 1,4 mil empregos diretos e indiretos na região. $O$ empreendimento é apoiado pelo programa de incentivo fiscal Paraná, Competitivo, do Governo do Estado, e vai impulsionar a arrecadação de 12 municípios do Norte Pioneiro e dos Campos Gerais.

Mais que apontar a obrigação da empresa de investir em educação - porque foi ajudada por meio do Paraná Competitivo -, o trecho indica os benefícios da empresa para a região, principalmente como geradora de empregos. Desse modo, em tempos de crise econômica, não é difícil que um discurso que sobrepõe emprego a educação seja facilmente aceito.

\section{CONCLUSÃO}

É possível perceber que, para além do texto, há a defesa de privatização da educação e a diminuição do papel do Estado. É possível, também, compreender que isso não é dito de forma direta, talvez porque, se assim ocorrer, não encontre apoio popular e/ou político. É preciso levar em consideração que vários autores podem ter sua participação nesta matéria, mas, como ocorre nos órgãos governamentais, a aprovação para a publicação é com base nos segmentos políticos e partidários defendidos.

Apesar de não haver uma única forma de leitura dos textos e discursos, em Foucault encontra-se inquietude. É preciso sempre ir além do que as palavras estão a dizer superficialmente. $O$ rápido exercício de análise da matéria em questão serve para esse pensar e para refletir, também, sobre as investidas neoliberais, principalmente na área da educação.

\footnotetext{
${ }^{3}$ https://www.falconi.com/
} 


\section{REFERÊNCIAS}

FOUCAULT, M. A Ordem do Discurso. São Paulo: Edições Loyola, 2011.

GENTILI, P. A. A. Neoliberalismo e educação: manual do usuário. In: SILVA, T. T. da; GENTILI, P. A. A. (Org.). Escola S. A.: quem ganha e quem perda no mercado educacional do neoliberalismo. Brasília: CNTE, 1996. p. 9-49.

MENDONÇA, Camila Tecla Mortean. O Estado do Conhecimento na Educação Superior a Distância e a Intervenção dos Organismos Internacionais nas Políticas Públicas (2001 - 2014). Maringá, 2016. 140 f. Dissertação de mestrado - Programa de Pós-Graduação em Educação, Centro de Ciências Humanas, Letras e Arte, Universidade Estadual de Maringá, Maringá, 2016.

MORAES, R C. C. Neoliberalismo: de onde vem, para onde vai?. São Paulo: Senac, 2001.

SMITH, Adam. A Riqueza das Nações: investigação sobre sua natureza e suas coisas. Vol. 2. São Paulo: Abril Cultural, 1983.

VIANA, Maria José de Faria. Assistência social no contexto do pluralismo de bem-estar. Brasília, 2007. 354 f. Tese de Doutorado - Doutorado em Política Social, Departamento de Serviço Social, Universidade de Brasília, Brasília. 